\title{
Analysis of mRNA Levels of Ten Genes Under Water Stress in Triticum turgidum subsp. durum
}

\author{
Marouane Melloul ${ }^{1,2}$, Driss Iraqi ${ }^{3}$, Sripada M Udupa ${ }^{3,5}$, Gilles Erba ${ }^{4}$, My Abdelaziz El Alaoui ${ }^{1,2}$, Mohammed \\ Ibriz $^{1} \&$ Elmostafa El Fahime ${ }^{2}$ \\ ${ }^{1}$ Genetic and biometry Lab, Faculty of Sciences, University Ibn Tofail, Morocco \\ ${ }^{2}$ Functional genomic platform - Technical Unit (UATRS) - National Center for Scientific and Technological \\ Research (CNRST), Morocco \\ ${ }^{3}$ National Institute of Agronomical research, Rabat, Morocco \\ ${ }^{4}$ Labgene Scientific Instruments Bâtiment Athéna, France \\ ${ }^{5}$ ICARDA-INRA Collaborative Research Project, International Center for Agricultural research in the Dry \\ Areas (ICARDA), Rabat, Morocco \\ Correspondence: Elmostafa El Fahime, Functional genomic platform - Technical Unit (UATRS) - National \\ Center for Scientific and Technological Research (CNRST), Morocco. E-mail: elfahime@cnrst.ma
}

Received: October 16, 2013 Accepted: November 27, 2013 Online Published: December 2, 2013

doi:10.5539/jps.v3n1p65

URL: http://dx.doi.org/10.5539/jps.v3n1p65

\begin{abstract}
Drought is one of the major causes of dramatic yield loss in crop plants. Plants perceive and respond to stress. Upon perception of stress, a signal is communicated to downstream components resulting in change of gene expression and thereby of proteins required for the initial damage-repair and physiological re-programming for better adaptation. In this work, a set of 10 genes from Triticum turgidum subsp. durum, were tested for their expression under drought conditions. These drought responsive genes selected for expressional analyses can be classified into two groups. The first group includes functional proteins already known to be involved in the response to water stress such as late embryogenesis protein. The second group comprises protein factors involved in the regulation of signal transduction and gene expression, such as transcription factors. We have used the real-time quantitative PCR to monitor the expression patterns of these 10 genes in Triticum durum leaves under drought stress. The results showed a high quantitative up-regulation of some genes belonging to dehydrin, transcription factors (DREBS), cell wall polysaccharides and regulation of secretion categories. Moreover, the actin binding protein and an ethylene-responsive element binding factor genes were slightly down-regulated and not significantly affected by the drought stress. The result of this study extended our knowledge of drought induced genes and may provide better understanding of the molecular mechanisms of drought response inTriticum durum. Identifying genes turned on or off in response to water stress will help in enhancing drought tolerance and providing genes that can be tested by many biotechnology-based approaches. The long term objective of this study is to choose the optimum condition for subsequent whole transcriptomic analysis by cDNA-AFLP.
\end{abstract}

Keywords: drought, Triticum, dehydrins, DREBs, real time PCR, gene expression

\section{Introduction}

Abiotic stresses such as drought, salinity, extreme temperature are the major impediments restraining plant growth and resulting in significant reductions in crop productivity (Wang et al., 2003). Abiotic stresses lead to degradation of many proteins in the cell and synthesis of a small portion of proteins (Sachs et al., 1980). Among all abiotic stresses, drought is a major agronomic problem resulting in reduction in yields of crops exposed to constant or sporadic periods of drought (Somerville \& Briscoe, 2001; Chaves et al., 2003). Water stress is perceived as water deficit and can occur with different severity (Ramanjulu \& Bartels, 2002). Plants respond to this dehydration through modifications of their morphology and physiological processes. The response and adaptation of plants to such conditions are very complex and highly variable. Being sessile organisms, plants have developed various strategies to acquire stress tolerance. One of the major molecular responses that plants exhibit to drought stress is altered expression of genes, related to different pathways associated with stress 
perception, signal transduction, regulators and synthesis of a number of compounds (Ramanjulu \& Bartels, 2002; Sreenivasulu et al., 2007). The identification and characterization of genes induced under abiotic stresses is a common approach to understand the molecular mechanisms of stress tolerance in plants. In the recent years, rapid advances in genomic technologies have led to an increasing understanding of global gene expression under water stress in plants (Shinozaki \& Yamaguchi-Shinozaki, 2000; Ingram \& Bartels, 1996; Bray, 1997). The research on Arabidopsis implies that a significant proportion of the genome is involved in drought response (Shinozaki \& Yamaguchi-Shinozaki, 2000; Shinozaki et al., 2003). The transcriptome analyses using microarray technology (Seki et al., 2001; Bohnert et al., 2001; Zhu et al., 2001) have identified several genes induced by abiotic stresses, that were classified into two major groups (Shinozaki \& Yamaguchi-Shinozaki, 2000; Thomashow, 1999). The first group includes functional proteins or proteins that probably function in stress tolerance. They are late embryogenesis-abundant (LEA) proteins; heat-shock proteins; osmoprotectant biosynthesis related proteins; carbohydrate metabolism-related proteins; transporters; detoxification enzymes; antifreeze proteins; senescence-related genes; protease inhibitors; and lipid-transfer proteins. One important area of molecular studies on water stress has been focused on the identification and characterization of the late-embryogenesis-abundant (LEA) proteins (Ingram \& Bartels, 1996). LEA proteins were initially identified in plant seeds (Dure et al., 1981). Based on sequence similarity and conserved domains, LEA proteins have been classified into nine groups (Wise, 2003; Bies-Etheve et al., 2008). Some of the most studied LEA proteins in higher plants are the group 2 or dehydrins (Veeranagamallaiah et al., 2011; Yuxiu et al., 2007). Dehydrins are synthesized in the later stages of plant embryogenesis, when seeds are maturing and their water content is decreasing (Mtwisha et al., 1998). Dehydrins have a highly hydrophilic character; they function as water-binding molecules, stabilizing macromolecules and membranes (Wang et al., 2003). It has been suggested that they are involved in protecting cellular or molecular structures from the damaging effects of water loss by sequestration of ions, replacement of hydrogen bonding function of water or assisting protein refolding under stress conditions (Bray, 2002b). Many studies indicate that dehydrins are associated with macromolecules such as nucleoprotein complexes in the nucleus (Godoy et al., 1994) and endomembranes in the cytoplasm (Schneider et al., 1993). An immuno-localization study in wheat showed that dehydrins are associated with the plasma membrane (Goday et al., 1994). The second group includes transcription factors, secondary messengers, phosphatases and kinases such as mitogen-activated kinases (MAPKs), and calcium dependent protein kinases (CDPKs) (Ludwig et al., 2004) that regulate the expression of other genes in response to drought stress. Transcription factors are thought to be the most varied and major category because they act as direct or indirect regulators of drought-responsive gene expression (Bray, 2004). The DREB/CBFs transcription factors that belong to AP2/ERF super family are involved in plant response to environmental stresses such as cold and drought (Stockinger et al., 1997; Thomashow, 2001). They are considered as the best studied group of transcriptional factors involved in abiotic stress response. The DREB factors activate the expression of several target genes that are responsible for controlling correlated characters such as osmoprotection and metabolism (Lata \& Prasad, 2011; Hussain et al., 2011). These proteins can specifically bind to dehydration-responsive element (DRE)/C-repeat (CRT), and mediate transcription of target genes (Stockinger et al., 1997). It was shown that DREB factors activate the stress response through DREs in ABA-independent manner (Agarwal \& Jha, 2010). However, DREB proteins have been also reported to be engaged in an ABA-mediated gene expression pathway (Fujita et al., 2011; Xu et al., 2011). A secondmember of the AP2/ERF gene family plant transcription factors are ethylene-responsive element binding factors (ERFs) (Riechmann \& Meyerowitz, 1998). The ERF gene family of transcriptional factors is one of the largest transcriptional factor gene families in the plant kingdom (Riechmann and Meyerowitz 1998; Okamuro et al., 1997). ERFs are induced by a variety of stresses and pathogens, as well as by hormones associated with defense responses, such as ethylene, jasmonic acid (JA), and salicylic acid (SA) (Jaglo et al., 2001; Xu et al., 1998; Fujimoto et al., 2000). In this study durum wheat (Triticum turgidum L. var. durum), one of the staple food crops of the world was used for the analysis of gene expression under drought stress. In Morocco, it is an economically and nutritionally important cereal crop and ranks third after barley and bread wheat(Belaid et al., 2005). Durum wheat is traditionally grown under rainfed conditions in marginal environments of the semi-arid tropics. In these regions, water limitation is the most important production constraint (Simane \& Struik, 1993). Our aim has been to elucidate the dynamics of the transcription profiles of 10 genes under water stress in comparison with control plants using quantitative real-time PCR. The selected ten genes belonged to different functional categories: transcription factors (DREB and ERF), LEA2 (dehydrins), osmoprotectant (actin binding protein), cell wallpolysaccharide (xylanase inhibitors), cellular metabolism (aldehyde dehydrogenase) and regulation of secretion (HVA22). The objective of this study is to understand the molecular behavior of genes belonging to different functional categories, analyzed by means of a time course dehydration experiment in a controlled greenhouse conditions. Identifying genes expressed or repressed in 
response to water stress is useful for enhancing drought tolerance and providing genes for many biotechnology-based approaches. The long term objective of this work is to choose on the basis of physiological and molecular analyses during the time course experiment, the optimum stress condition to collect samples for the whole transcriptomic analysis by cDNA-AFLP.

\section{Materials and Methods}

\subsection{Plant Material and Drought Treatment}

Seeds from Triticum durum were transplanted into $3.0 \mathrm{~L}$ pot filled with $3 \mathrm{Kg}$ of sterilized field soil. The seedlings were grown under controlled conditions with $16 \mathrm{~h}$ daylight at $22{ }^{\circ} \mathrm{C}$ and an $8 \mathrm{~h}$ dark period at $20{ }^{\circ} \mathrm{C}$ in a greenhouse at INRA, Rabat, Morocco.

\subsubsection{Available Water Content (AWC)}

The drought treatment was started at the flowering stage by withholding water, and pots soil was allowed to dry until it reached $45 \%$ available water content (\%AWC). Plants were maintained at $45 \%$ AWC for 10 days. The soil moisture for the pots of the well-watered and drought stressed conditions was maintained with the required amounts of water by weighing pots and watering plants daily. A total of foursampling timeswere programmed for control and stressed samples: at 4 days (T4), 6 days (T6), 8 days (T8) and 10 days (T10) after the initiation of the stress treatment (45\% AWC).In parallel we collected the well watered samples (control plants) at T4, T6, T8, and T10 (e.g. for each stressed time we have a control sample).

\subsubsection{Leaf Relative Water Content (RWC)}

The physiological status of plants during the time-course was monitored by the RWC (González \& González-Vilar, 2003). The fresh weight (FW) was determined using two leaves just harvested. The turgid weight (TW) was measured after rehydration of the leaves by floating on distilled water in a closed petri dish for $6 \mathrm{~h}$, at $4{ }^{\circ} \mathrm{C}$, in the dark. The dry weight (DW) was evaluated after dehydration for $24 \mathrm{~h}$ at $80{ }^{\circ} \mathrm{C}$. Three biological replicates for each sampling time (T0, T4, T6, T8 and T10) were used.

\subsection{RNA Preparation and cDNA Synthesis}

Three biological replicates were prepared for each sample of the treatment and well watered (controls) conditions. Total RNA was extracted from leaves using the Spectrum Plant Total Kit (Sigma Aldrich, St Louis, US) in accordance with the manufacturer's instructions. To remove the genomic DNA contamination, a digestion by Ambion Turbo DNase (life technologies, US) was carried out on the RNA samples. RNA was quantified by spectrophotometry at $260 \mathrm{~nm}$ using Nanodrop 8000 (Thermo Scientific). The integrity of the RNA was checked on a $2 \%$ formamide denaturing gel. With SuperScript III reverse transcriptase (Invitrogen, Carlsbad, CA) and oligo (dT) 20 (Invitrogen), the first strand cDNA was synthesized using $2 \mu \mathrm{g}$ of total purified RNA.

\subsection{Real-Time quantitative PCR (RT-qPCR) Analysis}

First strand cDNA was used as template for qRT-PCR amplifications of the 10 selected genes. Primer pairs were designed for six selected genes using Primer 3.0 web resource on Triticum durum sequences available on GenBank. The 10 genes as well as reference genes and their primers are listed in Table 1. The real time PCR consisted of $10 \mu \mathrm{l} \mathrm{SYBR}$ green fast Ready Mix (Kapa Biosystems), $300 \mathrm{nM}$ forward and reverse primers, $200 \mathrm{ng}$ of cDNA and sterile distilled water to a total volume of $20 \mu$. The PCR amplification was programmed with an initial incubation at $95{ }^{\circ} \mathrm{C}$ for $3 \mathrm{~min}$, followed by 45 cycles of denaturation at $95{ }^{\circ} \mathrm{C}$ for $10 \mathrm{~s}$ and annealing at $60{ }^{\circ} \mathrm{C}$ for $30 \mathrm{~s}$. Melting curve analysis was performed to evaluate the presence of non-specific PCR products and primer dimers. The real time quantitative PCR was carried out on a RotorGene 6000 machine (Corbett Research, Sydney, Australia). The qPCR assays were performed according to the MIQE guidelines (Bustin et al., 2009). For each selected gene three biological replicates were assayed independently and reaction was performed in duplicate. To check the absence of genomic DNA contamination in RNA samples, we ran PCRs using the RNA samples without the reverse transcriptase enzymes (no RT-controls) using CDC (cell division control) specific primers. Five reference genes were tested by real time PCR to be used as internal control genes: wheat actin conserved region, cell division control (CDC), ADP-ribosylation factor (ADP-RF), RNase L inhibitor-like protein (RLIa) (Gimenez et al., 2011) and 26S ribosomal RNA(Ali-Benali et al., 2005). The GeNorm algorithm was used to calculate the gene stability $(M)$ for all reference genes (Vandesompele et al., 2002). The PCR efficiency of each gene was determined using five serial dilutions of cDNA templates (200, 40, 8, 1.6 and 0.32 ng). The relative expression levels were analyzed using the pfaffl method with efficiency correction (Pfaffl, 2001). Statistical analyses were carried out using the t-test to compare mean values. 
Table 1. Primers sequences for RT-qPCR

\begin{tabular}{|c|c|c|c|}
\hline $\begin{array}{c}\text { Genes (GenBank } \\
\text { accession number) }\end{array}$ & Forward & Reverse & Reference \\
\hline \multicolumn{4}{|l|}{ Reference genes } \\
\hline 26S rDNA (M37274) & CCGGTTGTTATGCCAATAGCA & GCGGCGCAGCAGTTCT & Ali-Benali et al., 2005 \\
\hline Wheat actin (Ta1868) & ACCTTCAGTTGCCCAGCAAT & CAGAGTCGAGCACAATACCAGTTG & Gimenez et al., 2011 \\
\hline RLI (a) (Ta2776) & TTGAGCAACTCATGGACCAG & GCTTTCCAAGGCACAAACAT & Gimenez et al., 2011 \\
\hline CDC(a) (Ta54227) & CAGCTGCTGACTGAGATGGA & ATGTCTGGCCTGTTGGTAGC & Gimenez et al., 2011 \\
\hline ADP_RF(a) (Ta2291) & TCTCATGGTTGGTCTCGATG & GGATGGTGGTGACGATCTCT & Gimenez et al., 2011 \\
\hline \multicolumn{4}{|l|}{$L E A$} \\
\hline Td11 (AJ890140) & AGGTGATCGATGACAACGGTG & ACCCTCGGTGTCCTTGTGG & Ali-Benalietal., 2005 \\
\hline Td16 (X78429) & AGATGCAGTAAAACTTCCCGAAAT & CCCGGGTACATACAAGCAGC & Ali-Benali et al., 2005 \\
\hline \multicolumn{4}{|l|}{ Transcription factors } \\
\hline \multicolumn{4}{|l|}{ TdDRF1.1 } \\
\hline $\begin{array}{c}\text { TdDRF1.2 } \\
\text { (DQ011890) }\end{array}$ & CATGACGGTAGATCGGAA & TGCACAGGGAAGTTGGTA & Latini et al., 2007 \\
\hline $\begin{array}{c}\text { ERF } \\
(\text { GAKM01042787.1) }\end{array}$ & GCCTTCCGAGGACTAGACAAAG & AGGACCAGAACAGAAGAAGGAAAA & This work \\
\hline \multicolumn{4}{|l|}{ Osmoprotectant } \\
\hline $\begin{array}{l}\text { Actin binding protein } \\
\text { (Wcor719) } \\
(\mathrm{BF} 293720)\end{array}$ & CCGTCTACGACCTGGACTTC & CGTGATGGACGGATTAGCTT & This work \\
\hline \multicolumn{4}{|l|}{ Cellular metabolism } \\
\hline $\begin{array}{c}\text { Aldehyde } \\
\text { dehydrogenase } \\
(\mathrm{ALDH7})(\mathrm{AJ} 614830)\end{array}$ & CTTGCCAAGTGCAATCTTCA & ATGGCGTTGTTCCCACTAAG & This work \\
\hline \multicolumn{4}{|l|}{$\begin{array}{c}\text { Cell wall and } \\
\text { polysaccharide } \\
\text { metabolism }\end{array}$} \\
\hline $\begin{array}{l}\text { Xylanase inhibitor } \\
\text { (AJ613017) }\end{array}$ & GCGCTCATCGTCGGCCTCTC & CCGTGAAGTTCGTCCCGCCC & This work \\
\hline $\begin{array}{l}\text { endo beta } 1.4 \\
\text { glucanase } \\
(\mathrm{CV} 760011)\end{array}$ & TCCGTCAGCGGCTACCACGA & CCGGGTGGCGAGGATCTGGA & \\
\hline \multicolumn{4}{|l|}{$\begin{array}{l}\text { Regulation of } \\
\text { secretion }\end{array}$} \\
\hline HVA22 (BE429327) & ATGAGCAAGCTCTGGACGAT & GCGTGACGAAGGAGTAGAGG & This work \\
\hline
\end{tabular}

\section{Results and Discussion}

\subsection{Physiological Analysis}

The stress effects, on the physiological status of plants, were monitored by the RWC to assess the effectiveness of the stress protocol applied and to evaluate its effects (Jones, 2007). The samples analysed in the absence of water stress, exhibited a RWC compatible with a non-stressed status (98\%). RWC values decreased significantly: $81.1 \%$ and $74.15 \%$ after $\mathrm{T} 6$ and $\mathrm{T} 8$ respectively and even further to $70 \%$ at $\mathrm{T} 10$ after water stress application. 
These results showed that the induced stress protocol affected the physiological status in the sample analyzed.

\subsection{Expression Profiling of the Internal Reference Genes}

Real time quantitative RT PCR was used to monitor the expression of 10 selected genes in Triticum durum under stress conditions. Reverse transcriptase (RT) followed by quantitative polymerase chain reaction is, at present, the most sensitive and, therefore, most used method for transcript abundance measurement (Ali-Benali et al., 2005; Roche et al., 2009; Degenkolbe et al., 2009). The relative quantification method was used to determine the relative expression of the 10 genes; the expression level was normalized to an internal reference gene(s). The choice and the validation of reference genes used to normalize the mRNA fraction are considered key points (Schmittgen \& Zakrajsek, 2000). A validation of reference genes was carried to identify which genes showing minimal variability under the experimental conditions used in the present study. The most stable expression genes under normal and stress conditions are CDC and ADP (Table 2); therefore they were chosen as internal reference genes. Since contamination with DNA would affect the results of real time RT-PCR, the no RT controls, were tested with CDC specific primers and no PCR products were obtained indicating that all RNAs were free of genomic DNA (Figure 1). The absence of non-specific PCR products and primer dimer artefacts was checked by melting curves for each gene; a sole, symmetric and sharp curve indicated that only one product was accumulated.Fold changes in gene expression were normalized to ADP and CDC reference genes and relative to the untreated controls (e.g: fold change of samples collected at T4 after stress treatment were normalized to ADP and CDC and relative to well-watered T4 samples). Significance differences between means within days at $\mathrm{P}<$ 0.05 and $\mathrm{P}<0.01$ were found. Up-regulation by 2 folds and down-regulation by 0.5 fold ( -2 fold) were considered as significance.

Table 2. Gene-stability values (M) of the reference genes analysed

\begin{tabular}{cc}
\hline Reference genes & Average expression stability $(\boldsymbol{M})$ \\
\hline Actin & 0.759 \\
26S & 0.647 \\
RLI (a) & 0.625 \\
ADP & 0.560 \\
CDC & 0.552 \\
\hline
\end{tabular}

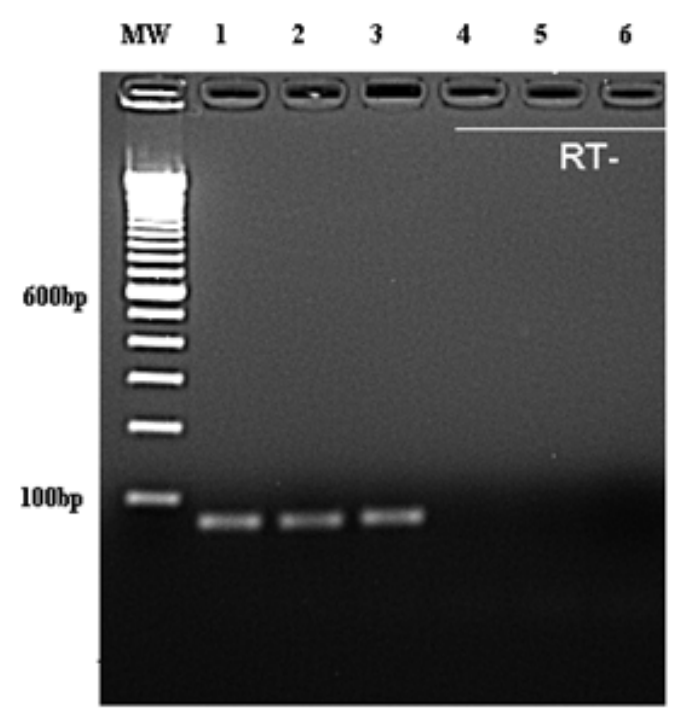

Figure 1. 2\% Agarose gel electrophoresis of some cell division control (CDC) PCR products (76bp) amplified from reverse transcribed RNAs (RT positive controls, lanes 1, 2 and 3) and RNAs without the reverse transcriptase enzyme (no-RT controls, lanes 4, 5 and 6). The gel showed a specific amplification of CDC amplicon in the RT positive controls and no band was detected in the RT negative controls). MW: $100 \mathrm{bp}$ molecular weight 


\subsection{Expression Profile of Genes Up- and Down-Regulated in Response to Water Stress}

Drought is the most important and prevalent abiotic stress during plant growth and development (Li et al., 2007). Water deficit has been found to alter plant gene expression and lead to specific gene induction (Ingram \& Bartels, 1996). Upon perception of the stress, the signal is communicated to the downstream components leading to the switching-on and/or switching-off the gene expression.In this study, Triticum durum was chosen to monitor the changes induced by water stress. As the regulation of gene expression is a dynamic process, we used real-time quantitative PCR analyses for the expression profiling of the selected ten genes over a time course, which allowed us to study their dynamic behavior and characterize their changes over time and under drought stress.A number of drought induced genes involved in a broad spectrum of biological pathways were chosen in the present study: Td11/T16 (dehydrins), actin binding protein (osmoprotectant), xylanase inhibitors/endo beta 1.4 glucanase (cell wall polysaccharide), HVA22 (regulation of secretion), ALDH7 (cellular metabolism), and DREB/ERF (transcription factors) (Table 1). Figure 2 shows the relative expression of the stressed and control plants for each time point of the water stress kinetics.

\subsection{Dehydrins (DHNs)}

Expression of genes encoding dehydrins was up-regulated in response to water deficit. At 4 days after stress treatment, mRNA levels of the Td11 gene were down-regulated and unchanged at T6 and T8 of stress in comparison with controls (Figure 2A), whereas no expression was detected in stressed and well watered plants for Td16 at T4 and T6 (Figure 2B). At 10 days after stress treatment, the Td11 gene was up-regulated approximately 2.76 -fold in response to water stress. Unlike Td11, the Td16 transcript was induced after 8 days of stress, reaching more than 2286-fold, with a large accumulation of a transcript (63156-fold) clearly detected after 10 days of stress treatment (Figure 2B). Consequently dehydrins proteins have different expression patterns in responses to drought stress. In a previous study (Ali-Benali et al., 2005) Td11 and Td16 were up regulated under water deficit in coleorhizae of Triticum durum seedlings, with the highest induction observed in Td16 (100.000-fold) after 2 days of water stress. Dehydrins are a family of plant proteins that are induced by stimuli that have a dehydrative component such as drought, low temperature, salinity, and ABA (Close, 1996). A wheat dehydrin has been shown to increase dehydration tolerance in transgenic rice (Cheng et al., 2002). In addition, drought-induced accumulation of dehydrin proteins has been associated with drought tolerance in many plant species, especially annual crops (Close et al., 1993; Lopez et al., 2001; Lopez et al., 2003). DHNs have been extensively studied in barley, where a dispersed family of 12 Dhn genes was characterized (Choi et al., 1999; Choi \& Close, 2000; Zhu et al., 2000). Most of the barley Dhn genes are up-regulated by dehydration and ABA, while others are cold-induced or embryo-specific. Also, the ectopic expression of a wheat dehydrin (DHN-5) in Arabidopsis plants improved their tolerance to high salinity and water deficit (Brini et al., 2007). Our results underline the fact that during drought stress, variations in pattern expression of dehydrin gene (LEA group2) are observed. We revealed that each of them exhibited a different transcription pattern in response to stress. Dehydrins belonging to the same family may respond differently to the same stress conditions. The dramatic increase of the Td16 gene in the current study indicate the importance of this gene in response to drought stress, thus the synthesis of dehydrins is a major part of global stress response to protect cell under water deficit.

\subsection{Osmoprotectant}

Actin binding proteins are essential for normal functioning of the actin cytoskeleton during plant growth and development (Barrero et al., 2002). Actin-binding proteins, are induced at the gene and protein levels in various cereals under osmotic stresses, and are speculated to have a role in signalling to $\mathrm{K}+$ channels (Yan et al., 2005). In our study the transcript expression of this protein was decreased to low levels $0.1,0.3$ and 0.4 fold at T4, T6 and T8 of stress application respectively (Figure 2C). At the 10th days of drought stress, the mRNA levels were unchanged in comparison with the controls. Based on microarray analysis on wheat (Mohammadi et al., 2007), actin binding protein was the most highly induced transcript detected in stressed roots. In contrast, the expression of this protein in barley under drought stress was up-regulated in roots but not in leaves (Oztur et al., 2002). Therefore our observations showed that tissue specific regulation occurs at protein level. 

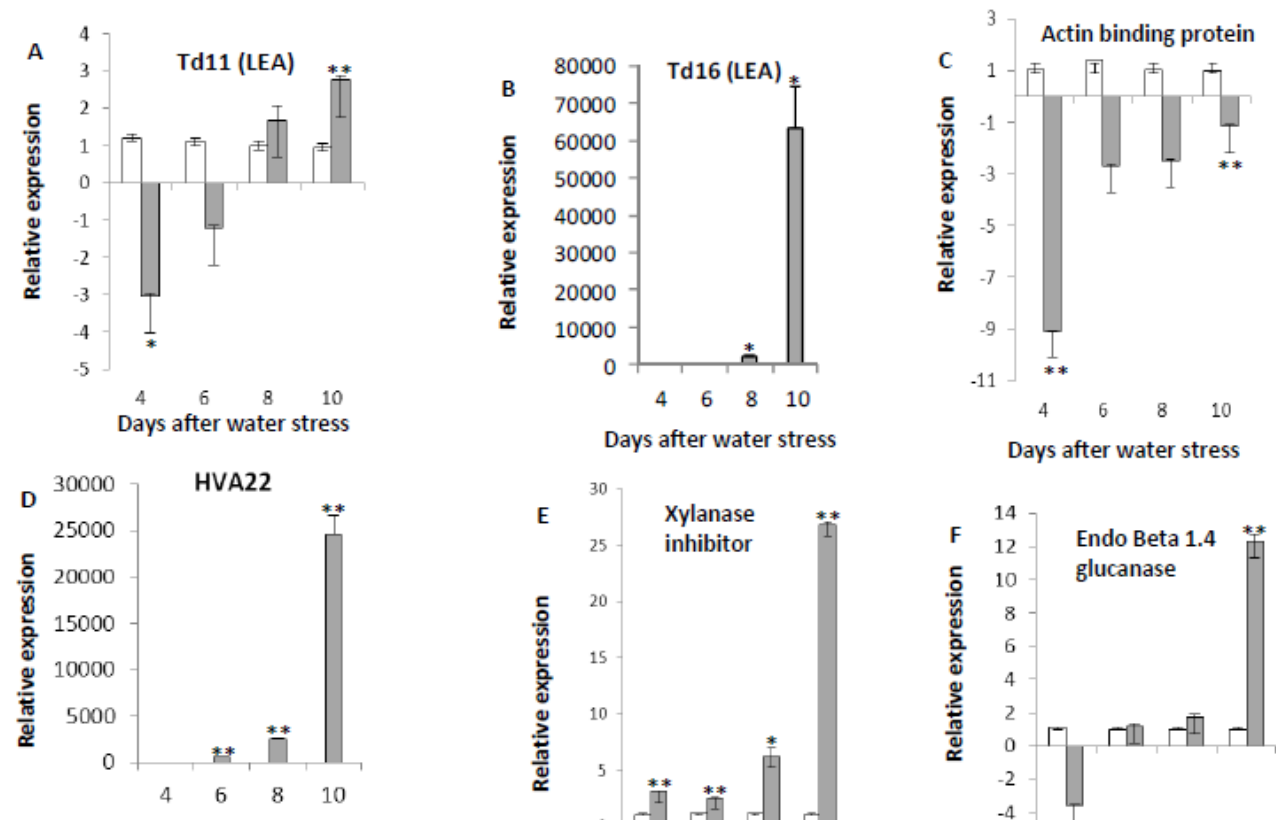

Days after water stress
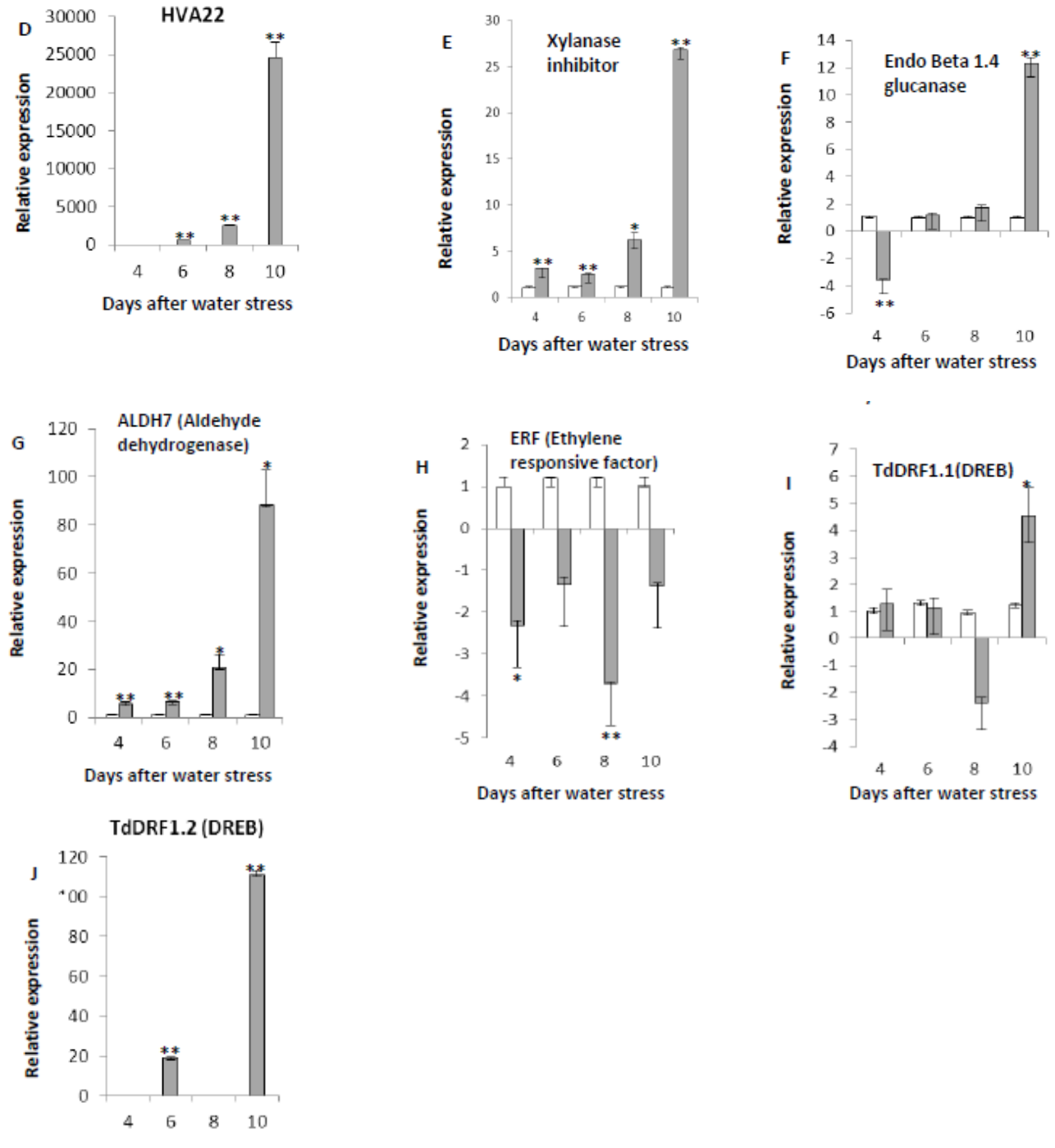

Days after water stress

Figure 2. Expressions pattern of the drought responsive genes by real time quantitative PCR. Data represent number of folds change of gene expression in stressed vs. control samples. The transcripts levels of each gene were monitored in Triticum durum leaves at 4, 6, 8, 10 days after water stress treatment was applied. Relative gene quantification was calculated by Pfaffl method. The fold change of the control samples (white bars) was approximately equal to 1 for the expressed genes.All data were normalized to theCDC and ADP expression levels. The mean expression value was calculated for every gene with three replications. Error bars show standard deviations of 3 biological replicates. Up-regulation by 2 folds and down-regulation by

0.5 fold $(-2)$ were considered as significance. One star $(*)$ : significance difference at $\mathrm{p}<0.05$; two stars $(* *)$ : highly significance difference at $\mathrm{p}<0.01$; no star: not significance difference observed. Three independent biological replicates were used for each samples for the analysis A: Td11 (LEA2) gene; B: Td16 (LEA2); C: Actin Binding Protein gene; D: HVA22; E: Xylanase inhibitor; F: Endo beta 1.4 glucanase; G: ALDH7 (Aldehyde dehydrogenase); H: ERF (Ethylene responsive factor); 


\subsection{Regulation of Secretion}

Abscisic acid (ABA) mediates various important plant developmental and physiological processes and also plant responses to stress conditions (Zeevaart \& Creelman, 1988). The gene HVA22 was originally identified as a transcript that accumulates in barley (Hordeum vulgare) aleurone tissue upon treatment with ABA, and was later found to be induced in vegetative tissues exposed to ABA, drought, or cold stress (Shen et al., 1993; Shen et al., 2001). In this work, we found that the HVA22 transcript expression was highly induced following treatment with drought. As shown in Figure2D, there was a strong accumulation (650-fold) after 6 days of stress application, and was further elevated 2468 and 24547-fold after 8 and 10 days of water stress respectively. No expression was detected at T4 after stress and in control plants. In Arabidopsis thaliana, transcripts of HVA22 homologs in leaves are highly induced by ABA, drought, cold, and salt stresses (Chen et al., 2002). Our results showed that drought stress significantly affected the expression of HVA22 and this effect was time-dependent. In plants, the level of tolerance or sensitivity to water stress are influenced by the developmental age of the plant, organ or tissue, previous events of exposure to stress, and chiefly by genetic variability (Bray, 2002a). The time of exposure and severity of stress is also very important for plant survival under drought conditions (Passioura 2007). The sharp increase of HVA22 gene may suggest a significant implication in drought tolerance.

\subsection{Cell Wall and Polysaccharide}

The expression pattern of the xylanase inhibitor and endo beta 1.4 glucanase was affected by the drought treatment. At 4 and 6 days of stress the expression of the xylanase gene was up regulated approximately 3 fold over the controls, whereas no significant up or down-regulation was observed for the glucanase gene (Figures 2E and $2 \mathrm{~F}$ ). At $\mathrm{T} 8$ of treatment, the expression level of xylanase gene was increased, with no change for endo beta 1.4 glucanase mRNA. After 10 days of stress, the two cell wall genes peaked, reaching 26 -fold (xylanase) and 12 -fold (glucanase) in comparison with the well watered control plants.Transcripts encoding proteins related to metabolism of polysaccharides, and especially cell wall polymers, are known to be responsive to osmotic stress (SAHI et al., 2006). Xylanase inhibitors and glucanases have been previously associated with stress tolerance in several species, including cereals (Hwang du et al., 2007; Lasanthi-Kudahettige et al., 2007). Overexpression of a xylanase inhibitor was reported to confer increased osmotic stress tolerance on Arabidopsis (Hong \& Hwang, 2006). In general, transcripts of the two cell wall proteins in this study were up-regulated by our water-withholding treatment, suggesting a change in cell wall extensibility or cellular components protection from water stress. In any case, the increase in transcript abundance is indicative of a significant role in stress tolerance.

\subsection{Cellular Metabolism}

During our time course experiment, the expression of Aldehyde dehydrogenases (ALDH7) changes, which reflect sensing of the water deficit by the plant; the fold changes from 5 to 88 (Figure 2G). The highest expression was detected at 10 days of stress treatment.ALDH genes are present in genomes of all organisms analyzed to date, implicating the importance of these enzymes in general biological functions. The ALDH superfamily includes the $\mathrm{NAD}(\mathrm{P})+$-dependent enzymes that oxidize a wide spectrum of endogenous and exogenous aldehydes (Lindahl, 1992). While some ALDHs have been described as part of this antioxidant defense system, other drought and salt stress-induced ALDHs seem to play a direct role in cellular osmoregulation by catalyzing the synthesis of osmoprotectants (Kirch et al., 2004). The aldehyde dehydrogenase gene is known to be up-regulated by abiotic stress (Figueroa-Soto \& Valenzuela-Soto, 2001). Overexpression of the aldehyde dehydrogenase AtALDH3 gene in Arabidopsis conferred tolerance to drought and salt stress (Sunkar et al., 2003). Several studies indicate that over-expression of some plant ALDHs enhances plant tolerance to diverse abiotic stresses (Kotchoni et al., 2006; Rodrigues et al., 2006; Huang et al., 2008). Among the ALDH families, ALDH7 proteins already described in plants have been shown to be induced by dehydration and salinity (Guerrero et al., 1990; Stroeher et al., 1995; Kirch et al., 2005). Ectopic expression of ALDH7 in both Arabidopsis and tobacco confers protection against various forms of osmotic stress, including dehydration and high salinity (Rodrigues et al., 2006). Interestingly, the ALDH7 selected for this study displayed high levels of expression under water stress suggesting that this gene has a possible role in improving the plant osmotic stress tolerance.

\subsection{Transcription Factors}

Transcription factors are of importance for plants to adapt to the environmental changes (Chen \& Zhu, 2004). Two transcripts (TdDRF1.1 and TdDRF1.2) produced by the TdDRF1 gene (DREB gene family) (Latini et al., 2007) and an ERF transcription factor (Mohammadi et al., 2007) were chosen for this study. The ERF chosen represents putative dehydration-inducible transcription factors that have been newly described in wheat, and may 
have an uncharacterized role as a negative transcriptional regulator (Mohammadi et al., 2007). The microarray and real time PCR data showed an inducible expression upon water deficit in hexaploid wheat roots. In our study, ERF gene expression in leaves was not affected during the time course experiments, being only slightly down-regulated at 4 and 8 days of stress application (Figure $2 \mathrm{H}$ ). These divergent results could be explained by differences of stress response in the plant tissue studied, the specific stress condition or even the species studied. In other studies, some members of ERF respond to abiotic stresses, such as drought and high salinity (Fujimoto et al., 2000; Park et al., 2001), and can confer tolerance to these stresses by overexpression in transgenic plants (Park et al., 2001).

Conversely, the transcripts of DERB gene family were up-regulated upon application of drought stress. The transcript TdDRF1.1 showed a constant expression level during the stress experiment with a slight decrease after 8 days, and an up-regulation 4 times after 10 days of stress (4-fold) compared with controls (Figure 2I); whereas, the transcript TdDRF1.2 was induced after 6 days upon water stress (19-fold), and no expression was detected in control samples (Figure 2J). A striking observation was that this transcript completely switched off immediately after 8 days of water stress, but was again switched on after 10 days (110-fold) of treatment. The reason for this 'on and off' of this gene remains unclear at present. A. Latini isolated and characterized the gene TdDRF1 in Triticum durum which produces three forms of transcripts through alternative splicing. Among the three isoforms, TdDRF1.2 was at all times the most expressed during water stress (Latini et al., 2007; Latini et al., 2008; Latini et al., 2013). In contrast, the upper expressions of this transcript during water stress; suggest its important role in stress response in Triticum durum. Many DREB1-type genes inserted into plants by transformation were capable of improving multiple abiotic stress tolerances in agricultural crops including tobacco (Kasuga et al., 2004), wheat (Pellegrineschi et al., 2004), rice (Dubouzet et al., 2003), and potato (Pino et al., 2008). Transgenic Arabidopsis constitutively overexpressing DREB1s/CBFs display significantly improved tolerance to freezing, drought and high salinity (Liu et al., 1998; Gilmour et al., 1998; Jaglo-Ottosen et al., 1998). An active form of DREB2 was shown to transactivate target stress-inducible genes and improve drought tolerance in transgenic Arabidopsis (Sakuma et al., 2006). In addition, DREBs are considered as candidate genes for stress tolerance engineering and to develop stress tolerant crop varieties (Lata \& Prasad, 2011).

A key to progress towards breeding better crops under stress has been to understand the changes in cellular, biochemical and molecular machinery that occur in response to stress. Expression profiling has become an important tool to understand the plant's response under adverse environmental conditions. Our study suggests that Triticum durum can effectively re-program globally the regulated expression of several genes under drought stress. The upper expression of these genes may lead to water deficit tolerance and suitable cellular response to avoid water deficit damage through several mechanisms in leaves. These results could also facilitate the understanding of cellular mechanisms involving groups of gene that act in coordination in response to water stress. Most of the responsive genes selected were significantly affected by drought treatment and this effect was time-dependent. This study clearly demonstrated that different genes were expressed or repressed at different time periods of drought stress and the level of the response of the same gene was drastically changed during the time course experiment. Three of the genes studied (Td16, HVA22 and TdDRF1.2), were induced by the drought treatment, probably resulting in increased levels of several metabolites and proteins, some of which may be responsible for conferring a certain degree of protection to this stress. The strongest accumulations was observed at 10 days of stress application suggesting that the intensity of drought stress may affect gene expression patterns when Triticum durum is exposed to longer periods of drought stress. In this study the genes Td16, HVA22 and TdDRF1.2 may be considered as candidate for possible genetic engineering targets for crop improvement. We have initiated this preliminary project as part on an ongoing investigation for the identification of stress specific genes, by isolating the differentially expressed genes which will provide a clear picture of the transcriptome under drought stress, using a genome wide investigation approach, the cDNA-AFLP. On the basis of the molecular analysis in this study, we were be able to choose the optimum conditions for the subsequent cDNA-AFLP analysis. As most genes peaked at 10 days after stress imposition, this condition is chosen to identify drought responsive genes, to gain a better understanding of stress responses. These investigations are in progress for providing more details and better understanding of stress responses. The findings will add new information to the broad picture of activated genes, and can also be considered as the starting point for further analysis of gene expression under drought stress.

\section{Acknowledgements}

This work was supported by the National Center for Scientific and Technological Research (CNRST). The authors would like to thank Sanaa Alaoui and Naima Lahlouhi for their technical assistance. 


\section{References}

Agarwal, P. K., \& Jha, B. (2010). Transcription factors in plants and ABA dependent and independent abiotic stress signalling. Biol Plant, 54(2), 201-212. http://dx.doi.org/10.1007/s10535-010-0038-7

Ali-Benali, M. A., Alary, R., Joudrier, P., \& Gautier, M. F. (2005). Comparative expression of five Lea Genes during wheat seed development and in response to abiotic stresses by real-time quantitative RT-PCR. Biochimica et biophysica acta, 1730(1), 56-65. http://dx.doi.org/10.1016/j.bbaexp.2005.05.011

Barrero, R. A., Umeda, M., Yamamura, S., \& Uchimiya, H. (2002). Arabidopsis CAP regulates the actin cytoskeleton necessary for plant cell elongation and division. The Plant cell, 14(1), 149-163. http://dx.doi.org/10.1105/tpc.010301

Belaid, A., Nsarellah, N., Laamari, A., Nachit, M., \& Amri, A. (2005). Assessing the economic impact of durum wheat research in Morocco. International Center for Agricultural Research in the Dry Areas, 51.

Bies-Etheve, N., Gaubier-Comella, P., Debures, A., Lasserre, E., Jobet, E., Raynal M, ... Delseny, M. (2008). Inventory, evolution and expression profiling diversity of the LEA (late embryogenesis abundant) protein gene family in Arabidopsis thaliana. Plant molecular biology, 67(1-2), 107-124. ttp://dx.doi.org/10.1007/s11103-008-9304-x

Bohnert, H. J., Ayoubi, P., Borchert, C., Bressan, R. A., Burnap, R. L., Cushman, J. C., ... Zhu, J. K. (2001). A genomics approach towards salt stress tolerance. Plant Physiology and Biochemistry, 39(3), $295-311$. http://dx.doi.org/10.1016/S0981-9428(00)01237-7

Bray, E. A. (1997). Plant responses to water deficit. Trends in plant science, 2(2), $48-54$. http://dx.doi.org/10.1016/S1360-1385(97)82562-9

Bray, E. A. (2002a). Abscisic acid regulation of gene expression during water-deficit stress in the era of the Arabidopsis genome. Plant, cell \& environment, $25(2), \quad 153-161$. http://dx.doi.org/10.1046/j.1365-3040.2002.00746.x

Bray, E. A. (2002b). Classification of genes differentially expressed during water-deficit stress in Arabidopsis thaliana: an analysis using microarray and differential expression data. Annals of botany, 89, 803-811. http://dx.doi.org/10.1093/aob/mcf104

Bray, E. A. (2004). Genes commonly regulated by water-deficit stress in Arabidopsis thaliana. Journal of experimental botany, 55(407), 2331-2341. ttp://dx.doi.org/10.1093/jxb/erh270

Brini, F., Hanin, M., Lumbreras, V., Amara, I., Khoudi, H., Hassairi, A., ... Masmoudi, K. (2007). Overexpression of wheat dehydrin DHN-5 enhances tolerance to salt and osmotic stress in Arabidopsis thaliana. Plant cell reports, 26(11), 2017-2026. http://dx.doi.org/10.1007/s00299-007-0412-x

Bustin, S. A., Benes, V., Garson, J. A., Hellemans, J., Huggett, J., Kubista, M., ... Wittwer, C. T. (2009). The MIQE guidelines: minimum information for publication of quantitative real-time PCR experiments. Clinical chemistry, 55(4), 611-622. http://dx.doi.org/10.1373/clinchem.2008.112797

Chaves, M. M., Maroco, J., \& Pereira, J. O. S. (2003). Understanding plant responses to drought : from genes to the whole plant. Functional Plant Biology, 30(3), 239-264. ttp://dx.doi.org/10.1071/FP02076

Chen, C. N., Chu, C. C., Zentella, R., Pan, S. M., \& Ho, T. H. (2002). AtHVA22 gene family in Arabidopsis: phylogenetic relationship, ABA and stress regulation, and tissue-specific expression. Plant molecular biology, 49(6), 633-644. http://dx.doi.org/10.1023/A:1015593715144

Chen, W. J., \& Zhu, T. (2004). Networks of transcription factors with roles in environmental stress response. Trends in plant science, 9(12), 591-596. http://dx.doi.org/10.1016/j.tplants.2004.10.007

Cheng, Z., Targolli, J., Huang, X., \& Wu, R. (2002). Wheat LEA genes, PMA80 and PMA1959, enhance dehydration tolerance of transgenic rice (Oryza sativa L.). Molecular Breeding, 10(1-2), 71-82. http://dx.doi.org/10.1023/A:1020329401191

Choi, D. W., \& Close, T. J. (2000). A newly identified barley gene, Dhn12, encoding a YSK2 DHN, is located on chromosome $6 \mathrm{H}$ and has embryo-specific expression. Theoretical and Applied Genetics, 100(8), 1274-1278. http://dx.doi.org/10.1007/s001220051434

Choi, D. W., Zhu, B., \& Close, T. J. (1999). The barley (Hordeum vulgare L.) dehydrin multigene family: sequences, allele types, chromosome assignments, and expression characteristics of 11 Dhn genes of cv Dicktoo. Theoretical and Applied Genetics, 98(8), 1234-1247. http://dx.doi.org/10.1007/s001220051189 
Close, T. J. (1996). Dehydrins: Emergence of a biochemical role of a family of plant dehydration proteins. Physiologia Plantarum, 97(4), 795-803. http://dx.doi.org/10.1111/j.1399-3054.1996.tb00546.x

Close, T. J., Fenton, R. D., \& Moonan, F. (1993). A view of plant dehydrins using antibodies specific to the carboxy terminal peptide. Plant molecular biology, 23(2), 279-286. http://dx.doi.org/10.1007/BF00029004

Degenkolbe, T., Do, P. T., Zuther, E., Repsilber, D., Walther, D., Hincha, D. K., \& Kohl, K. I. (2009). Expression profiling of rice cultivars differing in their tolerance to long-term drought stress. Plant molecular biology, 69(1-2), 133-153. http://dx.doi.org/10.1007/s11103-008-9412-7

Dubouzet, J. G., Sakuma, Y., Ito, Y., Kasuga, M., Dubouzet, E. G., Miura, S., .. Yamaguchi-Shinozaki, K. (2003). OsDREB genes in rice, Oryza sativa L., encode transcription activators that function in drought-, high-saltand cold-responsive gene expression. The Plant journal : for cell and molecular biology, 33(4), 751-763.

Dure, L., Greenway, S. C., \& Galau, G. A. (1981). Developmental biochemistry of cottonseed embryogenesis and germination: changing messenger ribonucleic acid populations as shown by in vitro and in vivo protein synthesis. Biochemistry, 20(14), 4162-4168. http://dx.doi.org/10.1021/bi00517a033

Figueroa-Soto, C. G., \& Valenzuela-Soto, E. M. (2001). Purification of a heterodimeric betaine aldehyde dehydrogenase from wild amaranth plants subjected to water deficit. Biochemical and biophysical research communications, 285(4), 1052-1058. http://dx.doi.org/10.1006/bbrc.2001.5286

Fujimoto, S. Y., Ohta, M., Usui, A., Shinshi, H., \& Ohme-Takagi, M. (2000). Arabidopsis ethylene-responsive element binding factors act as transcriptional activators or repressors of GCC box-mediated gene expression. The Plant cell, 12(3), 393-404. http://dx.doi.org/10.2307/3870944

Fujita, Y., Fujita, M., Shinozaki, K., \& Yamaguchi-Shinozaki, K. (2011). ABA-mediated transcriptional regulation in response to osmotic stress in plants. Journal of plant research, 124(4), 509-525. http://dx.doi.org/10.1007/s10265-011-0412-3

Gilmour, S. J., Zarka, D. G., Stockinger, E. J., Salazar, M. P., Houghton, J. M., \& Thomashow, M. F. (1998). Low temperature regulation of the Arabidopsis CBF family of AP2 transcriptional activators as an early step in cold-induced COR gene expression. The Plant journal: for cell and molecular biology, 16(4), 433-442. ttp://dx.doi.org/10.1046/j.1365-313x.1998.00310.x

Gimenez, M. J., Piston, F., \& Atienza, S. G. (2011). Identification of suitable reference genes for normalization of qPCR data in comparative transcriptomics analyses in the Triticeae. Planta, 233(1), 163-173. http://dx.doi.org/10.1007/s00425-010-1290-y

Goday, A., Jensen, A. B., Culianez-Macia, F. A., Mar, Alba, M., Figueras, M., Serratosa, J., ... Pages, M. (1994). The maize abscisic acid-responsive protein Rab17 is located in the nucleus and interacts with nuclear localization signals. The Plant cell, 6(3), 351-360. http://dx.doi.org/10.1105/tpc.6.3.351

Godoy, J. A., Lunar, R., Torres-Schumann, S., Moreno, J., Rodrigo, R. M., \& Pintor-Toro, J. A. (1994). Expression, tissue distribution and subcellular localization of dehydrin TAS14 in salt-stressed tomato plants. Plant molecular biology, 26(6), 1921-1934. http://dx.doi.org/10.1007/BF00019503

González, L., \& González-Vilar, M. (2003). Determination of Relative Water Content. In M. Reigosa Roger (Ed.) Handbook of Plant Ecophysiology Techniques (pp. 207-212). Netherlands: Springer. http://dx.doi.org/10.1007/0-306-48057-3_13

Guerrero, F. D., Jones, J. T., \& Mullet, J. E. (1990). Turgor-responsive gene transcription and RNA levels increase rapidly when pea shoots are wilted. Sequence and expression of three inducible genes. Plant molecular biology, 15(1), 11-26. http://dx.doi.org/10.1007/BF00017720

Hong, J. K., \& Hwang, B. K. (2006). Promoter activation of pepper class II basic chitinase gene, CAChi2, and enhanced bacterial disease resistance and osmotic stress tolerance in the CAChi2-overexpressing Arabidopsis. Planta, 223(3), 433-448. http://dx.doi.org/10.1007/s00425-005-0099-6

Huang, W., Ma, X., Wang, Q., Gao, Y., Xue, Y., Niu, X., ... Liu, Y. (2008). Significant improvement of stress tolerance in tobacco plants by overexpressing a stress-responsive aldehyde dehydrogenase gene from maize (Zea mays). Plant molecular biology, 68(4-5), 451-463. http://dx.doi.org/10.1007/s11103-008-9382-9

Hussain, S. S., Kayani, M. A., \& Amjad, M. (2011). Transcription factors as tools to engineer enhanced drought stress tolerance in plants. Biotechnology progress, 27(2), 297-306. http://dx.doi.org/10.1002/btpr.514

Hwang, du. H., Kim, S. T, Kim, S. G., \& Kang, K. Y. (2007). Comprehensive analysis of the expression of twenty-seven beta-1, 3-glucanase genes in rice (Oryza sativa L.). Molecules and cells, 23(2), 207-214. 
Ingram, J., \& Bartels, D. (1996). THE MOLECULAR BASIS OF DEHYDRATION TOLERANCE IN PLANTS. Annu Rev Plant Physiol Plant Mol Biol, 47, 377-403. http://dx.doi.org/10.1146/annurev.arplant.47.1.377

Jaglo-Ottosen, K. R., Gilmour, S. J., Zarka, D. G., Schabenberger, O., \& Thomashow, M. F. (1998). Arabidopsis CBF1 overexpression induces COR genes and enhances freezing tolerance. Science (New York, NY), 280(5360), 104-106. http://dx.doi.org/10.1126/science.280.5360.104

Jaglo, K. R., Kleff, S., Amundsen, K. L., Zhang, X., Haake, V., Zhang, J. Z., ... Thomashow, M. F. (2001). Components of the Arabidopsis C-repeat/dehydration-responsive element binding factor cold-response pathway are conserved in Brassica napus and other plant species. Plant physiology, 127(3), 910-917. http://dx.doi.org/10.1104/pp.010548

Jones, H. G. (2007). Monitoring plant and soil water status: established and novel methods revisited and their relevance to studies of drought tolerance. Journal of experimental botany, 58(2), 119-130. $\mathrm{http}: / / \mathrm{dx}$. doi.org/10.1093/jxb/erl118

Kasuga, M., Miura, S., Shinozaki, K., \& Yamaguchi-Shinozaki, K. (2004). A combination of the Arabidopsis DREB1A gene and stress-inducible rd29A promoter improved drought- and low-temperature stress tolerance in tobacco by gene transfer. Plant \& cell physiology, 45(3), 346-350. http://dx.doi.org/10.1093/pcp/pch037

Kirch, H. H., Bartels, D., Wei, Y., Schnable, P. S., \& Wood, A. J. (2004). The ALDH gene superfamily of Arabidopsis. Trends in plant science, 9(8), 371-377. ttp://dx.doi.org/10.1016/j.tplants.2004.06.004

Kirch, H. H., Schlingensiepen, S., Kotchoni, S., Sunkar, R., \& Bartels, D. (2005). Detailed expression analysis of selected genes of the aldehyde dehydrogenase (ALDH) gene superfamily in Arabidopsis thaliana. Plant molecular biology, 57(3), 315-332. http://dx.doi.org/10.1007/s11103-004-7796-6

Kotchoni, S. O., Kuhns, C., Ditzer, A., Kirch, H. H., \& Bartels, D. (2006). Over-expression of different aldehyde dehydrogenase genes in Arabidopsis thaliana confers tolerance to abiotic stress and protects plants against lipid peroxidation and oxidative stress. Plant, cell \& environment, 29(6), 1033-1048. http://dx.doi.org/10.1111/j.1365-3040.2005.01458.x

Lasanthi-Kudahettige, R., Magneschi, L., Loreti, E., Gonzali, S., Licausi, F., Novi, G., ... Perata, P. (2007). Transcript profiling of the anoxic rice coleoptile. Plant physiology, 144(1), 218-231. http://dx.doi.org/10.1104/pp.106.093997

Lata, C., \& Prasad, M. (2011). Role of DREBs in regulation of abiotic stress responses in plants. Journal of experimental botany, 62(14), 4731-4748. http://dx.doi.org/10.1093/jxb/err210

Latini, A., Rasi, C., Sperandei, M., Cantale, C., Iannetta, M., Dettori, M., Ammar, K., \& Galeffi, P. (2007). Identification of a DREB-related gene in Triticum durum and its expression under water stress conditions. Annals of Applied Biology, 150(2), 187-195. http://dx.doi.org/10.1111/j.1744-7348.2007.00128.x

Latini, A., Sperandei, M., Cantale, C., Arcangeli, C., Ammar, K., \& Galeffi, P. (2013). Variability and expression profile of the DRF1 gene in four cultivars of durum wheat and one triticale under moderate water stress conditions. Planta, 237(4), 967-978. http://dx.doi.org/10.1007/s00425-012-1816-6

Latini, A., Sperandei, M., Sharma, S., Cantale, C., Iannetta, M., Dettori, M., ... Galeffi, P. (2008). Molecular analyses of a dehydration-related gene from the DREB family in durum, wheat and triticale. In C. Abdelly, M. Öztürk, M. Shraf \& C. Grignon (Eds.), Biosaline Agriculture and High Salinity Tolerance (pp. 287-295). Birkhäuser Basel.

Li, H. Y., Huang, S. H., Shi, Y. S., Song, Y. C., Zhao, J. R., Wang, F. G., ... Li, Y. (2007). Isolating Soil Drought-Induced Genes from Maize Seediing Leaves Through Suppression Subtractive Hybridization. Agricultural Sciences in China, 6(6), 647-651. http://dx.doi.org/10.1016/S1671-2927(07)60095-9

Lindahl, R. (1992). Aldehyde dehydrogenases and their role in carcinogenesis. Critical reviews in biochemistry and molecular biology, 27(4-5), 283-335. http://dx.doi.org/10.3109/10409239209082565

Liu, Q., Kasuga, M., Sakuma, Y., Abe, H., Miura, S., Yamaguchi-Shinozaki, K., \& Shinozaki, K. (1998). Two transcription factors, DREB1 and DREB2, with an EREBP/AP2 DNA binding domain separate two cellular signal transduction pathways in drought- and low-temperature-responsive gene expression, respectively, in Arabidopsis. The Plant cell, 10(8), 1391-1406. http://dx.doi.org/10.2307/3870648

Lopez, C. G., Banowetz, G., Peterson, C. J., \& Kronstad, W. E. (2001). Differential accumulation of a 24-kd dehydrin protein in wheat seedlings correlates with drought stress tolerance at grain filling. Hereditas, 


\section{5(2-3), 175-181. http://dx.doi.org/10.1111/j.1601-5223.2001.00175.x}

Lopez, C. G., Banowetz, G. M., Peterson, C. J., \& Kronstad, W. E. (2003). Dehydrin Expression and Drought Tolerance in Seven Wheat Cultivars. Crop Sci, 43(2), 577-582. http://dx.doi.org/10.2135/cropsci2003.0577

Ludwig, A. A., Romeis, T., \& Jones, J. D. (2004). CDPK-mediated signalling pathways: specificity and cross-talk. Journal of experimental botany, 55(395), 181-188. http://dx.doi.org/10.1093/jxb/erh008

Mohammadi, M., Kav, N. N., \& Deyholos, M. K. (2007). Transcriptional profiling of hexaploid wheat (Triticum aestivum L.) roots identifies novel, dehydration-responsive genes. Plant, cell \& environment, 30(5), 630-645. http://dx.doi.org/10.1111/j.1365-3040.2007.01645.x

Mtwisha, L., Brandt, W., McCready, S., Lindsey, G. G. (1998). HSP 12 is a LEA-like protein in Saccharomyces cerevisiae. Plant molecular biology, 37(3), 513-521. http://dx.doi.org/10.1023/A:1005904219201

Okamuro, J. K., Caster, B., Villarroel, R., Van Montagu, M., \& Jofuku, K. D. (1997). The AP2 domain of APETALA2 defines a large new family of DNA binding proteins in Arabidopsis. Proceedings of the National Academy of Sciences of the United States of America, 94(13), 7076-7081. http://dx.doi.org/10.1073/pnas.94.13.7076

Oztur, Z. N., Talame, V., Deyholos, M., Michalowski, C. B., Galbraith, D. W., Gozukirmizi, N., ... Bohnert, H. J. (2002). Monitoring large-scale changes in transcript abundance in drought- and salt-stressed barley. Plant molecular biology, 48(5-6), 551-573. http://dx.doi.org/10.1023/A:1014875215580

Park, J. M., Park, C. J., Lee, S. B., Ham, B. K., Shin, R., \& Paek, K. H. (2001). Overexpression of the tobacco Tsi1 gene encoding an EREBP/AP2-type transcription factor enhances resistance against pathogen attack and osmotic stress in tobacco. The Plant cell, 13(5), 1035-1046. http://dx.doi.org/10.2307/3871362

Passioura, J. (2007). The drought environment: physical, biological and agricultural perspectives. Journal of experimental botany, 58(2), 113-117. http://dx.doi.org/10.1093/jxb/erl212

Pellegrineschi, A., Reynolds, M., Pacheco, M., Brito, R. M., Almeraya, R., Yamaguchi-Shinozaki, K., \& Hoisington, D. (2004). Stress-induced expression in wheat of the Arabidopsis thaliana DREB1A gene delays water stress symptoms under greenhouse conditions. Genome / National Research Council Canada Genome / Conseil national de recherches Canada, 47(3), 493-500. http://dx.doi.org/10.1139/g03-140

Pfaffl, M. W. (2001). A new mathematical model for relative quantification in real-time RT-PCR. Nucleic Acids Res, 29(9), e45. http://dx.doi.org/10.1093/nar/29.9.e45

Pino, M. T., Skinner, J. S., Jeknic, Z., Hayes, P. M., Soeldner, A. H., Thomashow, M. F., \& Chen, T. H. (2008). Ectopic AtCBF1 over-expression enhances freezing tolerance and induces cold acclimation-associated physiological modifications in potato. Plant, cell \& environment, 31(4), 393-406. http://dx.doi.org/10.1111/j.1365-3040.2008.01776.x

Ramanjulu, S., \& Bartels, D. (2002). Drought- and desiccation-induced modulation of gene expression in plants. Plant, cell \& environment, 25(2), 141-151. http://dx.doi.org/10.1046/j.0016-8025.2001.00764.x

Riechmann, J. L., \& Meyerowitz, E. M. (1998). The AP2/EREBP family of plant transcription factors. Biological chemistry, 379(6), 633-646

Roche, J., Hewezi, T., Bouniols, A., \& Gentzbittel, L. (2009). Real-time PCR monitoring of signal transduction related genes involved in water stress tolerance mechanism of sunflower. Plant physiology and biochemistry: PPB / Societe francaise de physiologie vegetale, 47(2), 139-145.

Rodrigues, S. M., Andrade, M. O., Gomes, A. P., Damatta, F. M., Baracat-Pereira, M. C., \& Fontes, E. P. (2006). Arabidopsis and tobacco plants ectopically expressing the soybean antiquitin-like ALDH7 gene display enhanced tolerance to drought, salinity, and oxidative stress. Journal of experimental botany, 57(9), 1909-1918. http://dx.doi.org/10.1093/jxb/erj132

Sachs, M. M., Freeling, M., \& Okimoto, R. (1980). The anaerobic proteins of maize. Cell, 20(3), 761-767. http://dx.doi.org/10.1016/0092-8674(80)90322-0

SAHI, C., Chandan, S., Amanjot, B., \& Eduardo, G., Anil. (2006). Beyond osmolytes and transporters: novel plant salt-stress tolerance-related genes from transcriptional profiling data, vol 127. vol 1. Blackwell, Oxford, ROYAUME-UNI.

Sakuma, Y., Maruyama, K., Osakabe, Y., Qin, F., Seki, M., Shinozaki, K., \& Yamaguchi-Shinozaki, K. (2006). Functional analysis of an Arabidopsis transcription factor, DREB2A, involved in drought-responsive gene 
expression. The Plant cell, 18(5), 1292-1309. http://dx.doi.org/10.1105/tpc.105.035881

Schmittgen, T. D., \& Zakrajsek, B. A. (2000). Effect of experimental treatment on housekeeping gene expression: validation by real-time, quantitative RT-PCR. Journal of biochemical and biophysical methods, 46(1-2), 69-81. http://dx.doi.org/10.1016/S0165-022X(00)00129-9

Schneider, K., Wells, B., Schmelzer, E., Salamini, F., \& Bartels, D. (1993). Desiccation leads to the rapid accumulation of both cytosolic and chloroplastic proteins in the resurrection plant Craterostigma plantagineum Hochst. Planta, 189(1), 120-131. http://dx.doi.org/10.1007/BF00201352

Seki, M., Narusaka, M., Yamaguchi-Shinozaki, K., Carninci, P., Kawai, J., Hayashizaki, Y., \& Shinozaki, K. (2001). Arabidopsis encyclopedia using full-length cDNAs and its application. Plant Physiology and Biochemistry, 39(3), 211-220. http://dx.doi.org/10.1016/S0981-9428(01)01244-X

Shen, Q., Chen, C. N., Brands, A., Pan, S. M., \& Ho, T. H. (2001). The stress- and abscisic acid-induced barley gene HVA22: developmental regulation and homologues in diverse organisms. Plant molecular biology, 45(3), 327-340. http://dx.doi.org/10.1023/A:1006460231978

Shen, Q., Uknes, S. J., \& Ho, T. H. (1993). Hormone response complex in a novel abscisic acid and cycloheximide-inducible barley gene. The Journal of biological chemistry, 268(31), 23652-23660.

Shinozaki, K., \& Yamaguchi-Shinozaki, K. (2000). Molecular responses to dehydration and low temperature: differences and cross-talk between two stress signaling pathways. Current opinion in plant biology, 3(3), 217-223. http://dx.doi.org/10.1016/S1369-5266(00)80068-0

Shinozaki, K., Yamaguchi-Shinozaki, K., \& Seki, M. (2003). Regulatory network of gene expression in the drought and cold stress responses. Current opinion in plant biology, 6(5), 410-417. http://dx.doi.org/10.1016/S1369-5266(03)00092-X

Simane, B., \& Struik, P. C. (1993). Agroclimatic analysis: a tool for planning sustainable durum wheat (Triticum turgidum var. durum) production in Ethiopia. Agriculture, ecosystems and environment, 47(1), 31-36. http://dx.doi.org/10.1016/0167-8809(93)90134-B

Somerville, C., \& Briscoe, J. (2001). Genetic engineering and water. Science (New York, NY), 292(5525), 2217. http://dx.doi.org/10.1126/science.292.5525.2217

Sreenivasulu, N., Sopory, S. K., \& Kavi, K. P. B. (2007). Deciphering the regulatory mechanisms of abiotic stress tolerance in plants by genomic approaches. Gene, 388(1-2), 1-13. http://dx.doi.org/10.1016/j.gene.2006.10.009

Stockinger, E. J., Gilmour, S. J., \& Thomashow, M. F. (1997). Arabidopsis thaliana CBF1 encodes an AP2 domain-containing transcriptional activator that binds to the C-repeat/DRE, a cis-acting DNA regulatory element that stimulates transcription in response to low temperature and water deficit. Proceedings of the National Academy of Sciences of the United States of America, 94(3), 1035-1040. http://dx.doi.org/10.1073/pnas.94.3.1035

Stroeher, V. L., Boothe, J. G., \& Good, A. G. (1995). Molecular cloning and expression of a turgor-responsive gene in Brassica napus. Plant molecular biology, 27(3), 541-551. http://dx.doi.org/10.1007/BF00019320

Sunkar, R., Bartels, D., \& Kirch, H. H. (2003). Overexpression of a stress-inducible aldehyde dehydrogenase gene from Arabidopsis thaliana in transgenic plants improves stress tolerance. The Plant journal: for cell and molecular biology, 35(4), 452-464. http://dx.doi.org/10.1046/j.1365-313X.2003.01819.x

Thomashow, M. F. (1999). PLANT COLD ACCLIMATION: Freezing Tolerance Genes and Regulatory Mechanisms. Annu Rev Plant Physiol Plant Mol Biol, 50, 571-599. $\mathrm{http}: / / \mathrm{dx}$.doi.org/10.1146/annurev.arplant.50.1.571

Thomashow, M. F. (2001). So what's new in the field of plant cold acclimation? Lots! Plant physiology, 125(1), 89-93. http://dx.doi.org/10.1104/pp.125.1.89

Vandesompele, J., De Preter, K., Pattyn, F., Poppe, B., Van Roy, N., De Paepe, A., \& Speleman, F. (2002). Accurate normalization of real-time quantitative RT-PCR data by geometric averaging of multiple internal control genes. Genome biology, 3(7), RESEARCH0034. http://dx.doi.org/10.1186/gb-2002-3-7-research0034

Veeranagamallaiah, G., Prasanthi, J., Reddy, K. E., Pandurangaiah, M., Babu, O. S., \& Sudhakar, C. (2011). Group 1 and 2 LEA protein expression correlates with a decrease in water stress induced protein aggregation in horsegram during germination and seedling growth. Journal of plant physiology, 168(7), 
671-677. http://dx.doi.org/10.1016/j.jplph.2010.09.007

Wang, W., Vinocur, B., \& Altman, A. (2003). Plant responses to drought, salinity and extreme temperatures: towards genetic engineering for stress tolerance. Planta, 218(1), 1-14. http://dx.doi.org/10.1007/s00425-003-1105-5

Wise, M. J. (2003). LEAping to conclusions: a computational reanalysis of late embryogenesis abundant proteins and their possible roles. BMC bioinformatics, 4, 52. http://dx.doi.org/10.1186/1471-2105-4-52

Xu, P., Narasimhan, M. L., Samson, T., Coca, M. A., Huh, G. H, Zhou, J., ... Bressan, R. A. (1998). A nitrilase-like protein interacts with GCC box DNA-binding proteins involved in ethylene and defense responses. Plant physiology, 118(3), 867-874. http://dx.doi.org/10.1104/pp.118.3.867

Xu, Z. S., Chen, M., Li, L. C., \& Ma, Y. Z. (2011). Functions and application of the AP2/ERF transcription factor family in crop improvement. Journal of integrative plant biology, 53(7), 570-585. http://dx.doi.org/10.1111/j.1744-7909.2011.01062.x

Yan, S., Tang, Z., Su, W., \& Sun, W. (2005). Proteomic analysis of salt stress-responsive proteins in rice root. Proteomics, 5(1), 235-244. http://dx.doi.org/10.1002/pmic.200400853

Yuxiu, Z., Zi, W., \& Jin, X. (2007). Molecular mechanism of dehydrin in response to environmental stress in plant. Progress in Natural Science, 17(3), 237-246. http://dx.doi.org/10.1080/10020070612331343254

Zeevaart, J. A. D., \& Creelman, R. A. (1988). Metabolism and Physiology of Abscisic Acid. Annual Review of Plant Physiology and Plant Molecular Biology, 39(1), 439-473. http://dx.doi.org/10.1146/annurev.pp.39.060188.002255

Zhu, B., Choi, D. W., Fenton, R., \& Close, T. J. (2000). Expression of the barley dehydrin multigene family and the development of freezing tolerance. Mol Gen Genet, 264(1-2), 145-153. http://dx.doi.org/10.1007/s004380000299

Zhu, T., Budworth, P., Han, B., Brown, D., Chang, H. S., Zou, G., \& Wang, X. (2001). Toward elucidating the global gene expression patternsof developing Arabidopsis: Parallel analysis of 8 \&unknown;300<space>genesby a high-density oligonucleotide probe array. Plant Physiology and Biochemistry, 39(3), 221-242. http://dx.doi.org/10.1016/S0981-9428(00)01234-1

\section{Copyrights}

Copyright for this article is retained by the author(s), with first publication rights granted to the journal.

This is an open-access article distributed under the terms and conditions of the Creative Commons Attribution license (http://creativecommons.org/licenses/by/3.0/). 